\section{Designing with Families for Just Futures}

\author{
Ann M. Ishimaru \\ University of $W$ ashington
}

\author{
Megan Bang \\ Northwestern University
}

Journal of Family Diversity in

Education, 2021/2022

Vol. 4, No. 2, pp. 130-140

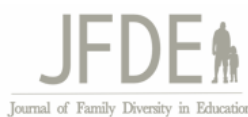

\section{$\underline{\text { ANN }}$}

Community, power, justice. These concepts have long been potent for me, not only as a scholar but also as a teacher, community organizer, cultural arts worker, mother, auntie, granddaughter, and Nikkei community member. To me, these concepts are anchored in questions about how we might become fully ourselves. How do we bring who we have been, what we know, and the community traumas, resilience, knowledge, and even privileges we now have to build a more just education and society? As a fourth-generation Japanese American, such questions are shaped by my family's culture and history, indelibly marked by our community's incarceration by our government during World War II for the crime of being ourselves.

Despite the uncertainty and betrayal at that time, my people created community and schools in the camps, built new lives afterwards in the face of racism and hatred, and then catalyzed a redress movement to try to ensure that the same thing cannot happen again to another community. And

\section{MEGAN}

Miigwechiwendan. Be grateful. Gizhewaadizi. Be kind, generous. Minwaajimo. Tell a good story. Minobimaadiziwin. The good life. Nandagikendan. Seek to learn it.

I come to this work, seeking to learn to live the good life, a just life, a sustainable life, as the mother of Ojibwe, Navajo, and Italian children, and in our ways, a mother and grandmother to many of my nieces and nephews who then extend my family to include Pima, Papago, Menominee, Potowatomi, Odawa, Oneida, Lakota, Mexican, Black and Iranian peoples. I am also a daughter, granddaughter, sister, and cousin. Some of these roles are through my blood relations, and some are made family.

My role in my families is made possible by those that came before me that struggled and endured, and continued to live. Those, like my grandfather, who survived boarding school, or my greatgrandparents, who watched their lands being seized and sold and relocated as they lived in the unfolding aftermath of the

\footnotetext{
Special Issue Guest Editors:

Ann M. Ishimaru, Ph.D., Associate Professor, University of Washington, College of Education, 2012 Skagit Lane, Seattle, WA, 98195, Email: aishi@uw.edu

Megan Bang, Ph.D., Professor, Northwestern University, Annenberg Hall, 2120 Campus Drive, Evanston, IL, 60208, Email: meganbang@northwestern.edu
} 
though the legacy of Japanese American incarceration continues to cast a long shadow on the language and cultural practices of our increasingly diverse community, those experiences also taught us lessons about gaman, our ability to "make something beautiful through your anger, with your anger, and neither erase it nor let it define you."1 We also learned about connections with other communities of color and Indigenous peoples on whose land we are simultaneously colonizers and colonized. The camps were often built on reservations, and my father was born on the Colorado River Indian Reservation in the camp known as Poston. As a fellow scholar wrote, we experienced for a few years what Indigenous communities have experienced for centuries. My father's family moved to Chicago after the war because a Black doctor there treated his asthma at a time when no white doctor would. I find myself reckoning with those histories as our community responds to anti-Asian racism that feels both new and ancient. Those histories are also present as we seek to move in solidarity with Black, Latinx, Indigenous, and Pacific Islander communities who have been disproportionately impacted by the pandemic - alongside Muslim and immigrant communities facing ongoing oppression. My family and community taught me to draw strength and wisdom from those who came before us, to claim our political voice in resisting injustice, to see our lives and struggles as fundamentally interdependent, and to work to build a better world kodomo no tame ni- "for the sake of the children." These lessons from my own family and community infuse how I entered the process of co-developing the Family Leadership Design Collaborative (FLDC).
Indian Act. An act that disfigured nationhood, severed familial bonds, and forced western patriarchal domination into the fibers of grandparent-parent-child relations through laws of belonging intended to cause relational violence. While the violence of these realities continues, it is also true that my family, past and present, continue to love, share stories, make art and music, grow and harvest food, pass on traditions, and make new ones. They have taught me to make life elsewhere to these violences, to fulfill our ancestral teachings and responsibilities in the here-and-now, and to continue to work to cultivate the conditions for our collective continuance.

Education has played a central role in our still-unfolding story. Education that has been saturated by settler colonialism and all of its dispossession and erasure, that removed through policy and violence, our communities forms of decision making about what our children learned, how they learned, why they learned, when they learned, and who taught them. Indeed recognized forms of education in the United States and Canada across history, whether through Christian missions, boarding schools, or public schooling, has continued to inflict onto-epistemic violence in stealthily muted and loud forms on Indigenous peoples intending to relegate our own forms of education to the shadows and the unceded time of what is often thought about as out of school learning. Dreaming, making, growing what could be, what we need anyway, is always also happening. After being a teacher, I served as the Director of Education of the American Indian Center of Chicago (AIC) for twelve years. AIC, like many urban Indian centers, is a place that is the essence of Native peoples resisting and refusing colonial harm, of insisting on collective

\footnotetext{
${ }^{1}$ From Traci Chee's young adult novel, "We are Not Free."
} 
The sensibilities and commitments I bring to the FLDC also grow out of my experiences as a parent that pushed me into a completely different relationship with schools relative to the one I had as a teacher. After attending my first open house as a parent, I felt infantilized and condescended to - and swore only halfjokingly never to attend another parent meeting! I understood in a visceral new way how well-meaning white educators can signal to parents of color that they are to blame if their child does not succeed in school, that professionals know what's best for their children.

Through my research (and prior work) in community organizing, though, I witnessed powerful, organized Black and Brown parents and community members enact leadership to reshape policies, school cultures, and everyday educational practices. Families and their children were at the center of these schools - not only physically present, but shaping decisions, mentoring teachers, fostering the leadership of other parents, collaborating with educators on disciplinary processes, conceptualizing grant proposals, or advocating for resources. In short, they were enacting the community organizing definition of leadership: taking responsibility for what matters. Leadership in and out of systems was key: not as power and authority tied to formal positions within school hierarchies but as collective action and influence enacted in deep relation to others and to histories of oppression, resistance, and cultural resiliencies -- like the leadership I learned in my own family and community contexts.

To learn our way towards educational justice and wellbeing, we need multiple forms of expertise. Families, their young people, and communities bring powerful untapped forms of expertise, not only through their histories and experiences of inequities but also through our relationships, cultural and linguistic continuance and communal wellbeing. A place birthed to continue community, culture, family, life, in the face of federal relocation policies intended to facilitate our assimilation. Instead, in this place, families came together to create the conditions where our stories and teachings lead us in creating learning environments and helped us to imagine and enact what we wanted for ourselves. While Indigenous people in urban communities reflect many tribal nations, in my experience, these processes of creating learning environments deepened, not erased or flattened, learning about our specific relationships and traditions. For me, I continued to deepen my understanding of my responsibilities as an Ojibwe woman and my ancestral teachings. I came to see the deep strength of engaging multiplicities and recognizing that the fear of assimilation and melting pot fantasies (e.g pan-indianism) can foreclose dreaming worlds forward. These fears can suffocate efforts to create decolonial education and cultivate our own resurgence through education. I have come to recognize the deep need to dislodge or desettle the foundational principles guiding much of education. Our current models, among other things, perpetuate age segregation, the removal of children from their familial and community life, and often deny family and communities roles and expertise in education.

Raising Indigenous children in the $21^{\text {st }}$ century to be good ancestors to future generations is, from my perspective, my central task and responsibility as a mother and as an educator. Being a good ancestor requires simultaneously to live our ways of knowing and being in the present, to honor and remember our histories, and to continually work to bring into being robust forms of life and wellbeing with our peoples, now and into the future. The Family Leadership Design Collaborative marks a new phase of work for me in which 
practices, knowledge, ethical stances, and ways of being in the world. Building from and weaving together those roots, we can begin to construct new solutions and work through possibilities for how communities and education might be.
I am aiming to help create solidarities across cultural communities that transform the foundational contradictions of education, that see generative tensions as key sites of change-making work to design, or dream anew, possible forms of education (and potentially policy) that contribute to multiple forms of community wellbeing and educational justice.

\section{Building the Family Leadership Design Collaborative}

As co-leads of the Family Leadership Design Collaborative, we open this special twopart section of JFDE with our own personal and scholarly narratives to situate the work of imagining just futures in the histories, struggles, understandings, and leadership of our own families and communities. The Family Leadership Design Collaborative (FLDC) was established in 2015 with the aim of cultivating a place and space to develop theories, everyday practices, and local policies to reach beyond the well-developed critique of conventional parent involvement regimes and into transformative possibilities. We intentionally enter the story of FLDC through our own stories as a way to model what it means to begin with our histories and ecologies as well as our scholarship in taking up what we have come to call "solidaritydriven codesign." Drawing from our collective ecologies, theories, and scholarship, a core group of scholars, family/community leaders, and educators came together to codesign a transformative research-practice agenda that would center families and communities in envisioning and leading racially just education (Ishimaru \& Bang, 2016). Our efforts built from Indigenous and decolonizing methodologies (Brayboy, 2005; Smith, 1999) as well as social justice-focused design-based research (such as social design experiments (Gutiérrez \& Jurow, 2016), formative interventions (Engeström, 2004), and community-based design (Bang et al., 2016). From these roots, we evolved solidarity-driven codesign, an iterative inquiry process with nondominant youth, families, and communities to envision and enact just relations and educational futures.

This introduction to the special two-part section of this journal shares the theoretical foundations of FLDC's work and the principles of solidarity-driven codesign that connect efforts across vastly different geographies, racial and ethnic communities, and contexts to reimagine ways forward towards educational justice. We illuminate methodological and theoretical trajectories of intertwined research and practice that seek to reckon with systems that have disregarded, alienated, and disproportionately harmed racially minoritized families and communities - and to envision paths forward centered on the priorities and dreams of those youth, families, and communities.

To reimagine the role of families and communities in racially equitable education, we first drew on critical race and decolonizing lenses to illuminate the settled expectations of the current school-centered paradigm and to build from ancestral and community practices to expand those aims towards a process of collective learning towards education justice and community wellbeing. With a network of collaborators, we worked to "lean in" to the generative tensions of decolonizing education in a way that fostered solidarity relations with each other and with local communities. We brought lenses from the study of culture, race, and learning into conversation with the critical educational leadership, school improvement, and 
family engagement fields to sharpen and expand the theoretical grounds for justice-focused change-making in education.

\section{Settled Expectations in Family Engagement}

We draw on Cheryl Harris' work on whiteness as property (Harris, 1993) to illuminate the settled expectations of family engagement that undergird the basic premises of schoolcommunity relations in US public schools. Dr. Harris analyzed the history of legal struggles and decisions to illuminate the intertwining of property rights and whiteness in the foundations of the United States, from the settler colonial logics of stolen lands from Indigenous peoples to the stolen labor of enslaved Africans kidnapped and brought by force to this country. She argued that the definitions of race (from "one drop" to "blood quantum") differ based on the property rights to be maintained, but they do so in ways that uphold the rights of those in power and sustain white institutional privilege, including the rights to determine meaning and the extent and pace of change:

"[T] he law holds to the basic premise that definition from above can be fair to those below, that beneficiaries of racially conferred privilege have the right to establish norms for those who have historically been oppressed pursuant to those norms, and that race is not historically contingent. Although the substance of race definitions has changed, what persists is the expectation of white-controlled institutions in the continued right to determine meaning - the reified privilege of power - that reconstitutes the property interest in whiteness in contemporary form." ( $p$ 1762).

In the case of family engagement, schools - as white-controlled institutions - have the right to define what counts (as "engagement" and "positive" support) and what doesn't and what matters (as learning and outcomes) and what doesn't. Schools retain the power to recognize, value, and reward practices that adhere to white, middle-class parenting norms and disregard, erase or pathologize others to legitimize and maintain a set of privileges and exclusivity in property. Thus, settled expectations in family engagement are normed on white, middle-class childrearing practices (Baquedano-López et al., 2013; McCarthy, 2019; Yull et al., 2018); departures from those norms are rendered detrimental to children because they threaten those meanings and privileges.

Part of these settled expectations include the unquestioned assumption that Black, Indigenous, Latinx, Asian, and Pacific Islander parents and families are, at best, passive clients or beneficiaries, not experts on their own children, educators in their own rights, or leaders in change-making. The underlying assumptions and dynamics of schools perpetuate dynamics in which mostly white educators seek to "fix" families to become compliance officers for schools - to ensure children's attendance and compliance with school policies - while expecting families to trust educators and school systems to keep their children safe, physically, emotionally, and psychologically.

\section{Decolonizing education: Leaning into the both/and of schools}

Powerful forms of resistance, (re)vitalization and survivance have always existed despite settler colonialism and oppression in the US (Kaba, 2021; Smith, 1999; Vizenor, 2008). Families of color have long educated their children towards becoming contributing, thriving members of their communities. These forms of learning continue in many ways, for example, through Indigenous stories and practices, nondominant collective childrearing practices, language preservation and revitalization efforts, African American liberatory education traditions, Latinx storytelling, and cultural practices, and parent racialization processes. Challenging and transforming the settled expectations of family engagement requires 
navigating inherent tensions and contradictions between fighting for the potential of public education in a pressing neoliberal policy context and cultivating the broader ecologies of learning across contexts essential for thriving beyond settled ends of meritocratic "escape" from one's community that so often is at the heart of "educational achievement."

In addition to recognizing the ancestral knowledges (Khalifa, 2018) and cultural "wealth" of communities of color (Yosso, 2005) then, efforts to transform the relationship between schools and families must reckon with the history of schools as sites of colonization built on stolen land, peoples and cultures, controlled by white educators, cultures, and structures. Compulsory attendance laws and policies of forced assimilation designed to separate children from their families, languages, knowledge, and ways of being (Fryberg \& Bang, 2018) have given way to policing of behaviors, subtle forms of segregated schooling, remediation paradigms, and the nexus between school and prisons (Andersons, 2011; LadsonBillings, 2006; Orfield \& Frankenburg, 2014; Love, 2019; Meiners, 2011). These recognitions raise pressing questions about whether foundations of oppression can foster liberation or justice. Envisioning education beyond those structures and their interconnected oppressive systems requires constructing new possibilities starting from a fundamentally different set of understandings, stances, and relations (Mignolo, 2007).

\section{Learning our way to education justice and community wellbeing}

Drawing from Black feminists who call us to move beyond either-or conceptualizations that subvert justice (hooks, 2003), we worked to move beyond static identities of "academics" versus "community" towards inviting each other to engage as whole human beings embedded in particular contexts as scholars, community leaders, family members, and educators. This was not a simple ask, given the histories of damage wrought by research in communities of color (Smith, 1999) and the powered racial, gender, and other hierarchies experienced by scholars of color in the academy (Niemann, 2012). In short, our practiced critique often led us to strategize change through negation (e.g., what's wrong or problematic that we should eliminate or strategize around), whereas we had not yet developed a shared practice of imagining beyond educational systems as they have been and currently exist - towards desired futures that might be.

By leaning into those tensions, we began to engage in collective learning and design that envisioned young people and families thriving in more expansive notions of education rooted in communities. We recognized that the aims of educational justice and community wellbeing cannot center schools and top-down policies or reforms but must be defined by each community within their own context. We pushed ourselves to build solidarities across communities and consider multiple theories of change for reimagining or working beyond existing systems. Although every community is distinct in its history, context, and nuances of culture, power, and relationality, the collaborative envisioned a set of principles that might collectively root and connect our efforts around a core set of stances and approaches.

\section{FLDC Solidarity-driven Design Principles}

We iteratively developed the following design principles to root subsequent inquiries across the collaborative in fostering educational justice and community wellbeing. Together we created a graphic (Cultural Organizing blog post) to help hold some of these principles, with each principle corresponding to a different aspect of the graphic (https:// familydesigncollab.org/framework/). Because we have elsewhere provided examples 
of practices that attend to the principles in specific contexts (Ishimaru et al., 2018), we focus here on the concepts and theoretical claims that inform the principles and their connections to one another.

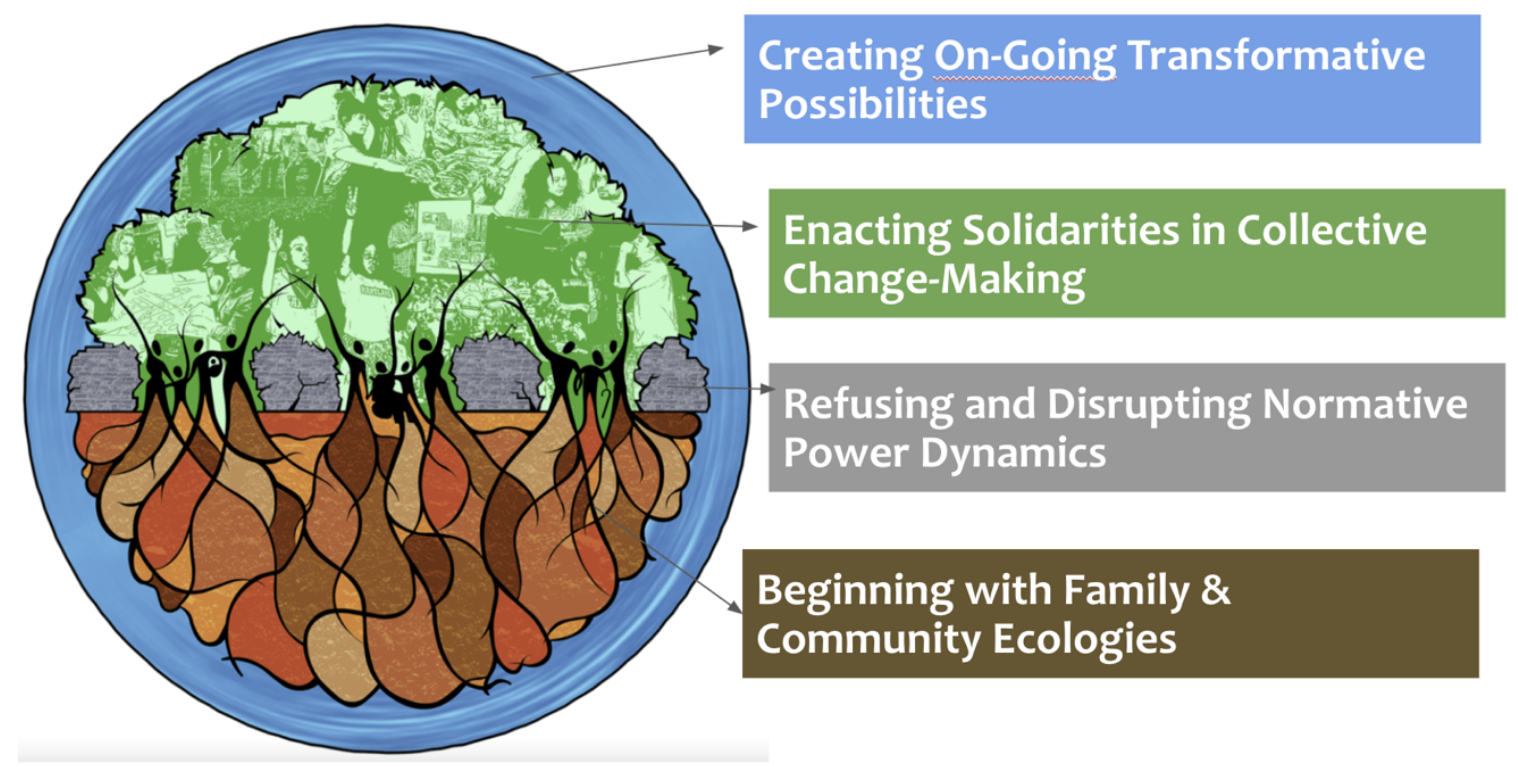

\section{Beginning with Family \& Community Ecologies}

Beginning at the bottom of the graphic, the foundations of justice and wellbeing must be rooted in the knowledge, priorities, practices, ethics, and relations of nondominant families \& communities. Starting codesign or process from an expansive understanding of those roots means situating work not only in histories and systems of oppression but also within ongoing forms of survivance (Vizenor, 2008) and resistance amidst settler colonialism and racism as well as histories of fugitivity, transformation and innovation in community spaces, both beyond and within formal institutions of education (Anderson, 2004; Cajete, 2016; Kelley, 2002; Siddle-Walker, 1996). In deliberately looking to ancestral knowledges, cultural practices, and lived experiences as resources in solidarity-driven codesign work with families and communities (Khalifa, 2018), we recognize nondominant communities as dynamic, multidimensional, and constantly evolving practices and knowledge across time and place. These stances recognize that the starting point for design and learning are consequential for the trajectories and pathways that open (or enclose) subsequent activity.

\section{Refusing and Disrupting Normative Power Dynamics}

Even as codesign roots itself in family and community ecologies, we also recognize current injustices in education (and society) as shaped by histories and power in systems, structures, and institutions that intersect differently across different positionalities. Thus, solidarity-driven codesign that reckons with power to transform it necessitates naming colonization, racism, colonialism, sexism, classism, ableism, and heteronormativity as root causes and intersectional forms of oppression. Beyond naming these dynamics and the barriers they constitute to thriving and dignity, codesign work seeks to "desettle" forms of normativity that function to assimilate and erase our cultural ways of knowing and being. Such forms of normativity include the settled expectations of nondominant families and communities we elaborated on earlier. Thus, this principle focuses on refusing and disrupting the normative processes or deliberations that position families as passive recipients or needy beneficiaries - 
but not knowers, doers, or leaders - while simultaneously positioning educators, policymakers, or researchers as unquestioned experts on the lives, learning, and futures of young people.

This principle also references our efforts to refuse an interest convergence politic in the process of our deliberations. Derrek Bell's notion of interest convergence illuminates how advances in racial justice occur only when they converge with the interests of powerful elites (Bell, 1980). Although Bell emphasized interest convergence as a historical tool for understanding societal change vis-à-vis racism, a dominant paradigm for change continues to rely on expanding white, powered interests to motivate change and shift institutions (Ishimaru \& Takahashi, 2017). However, interest convergence remains anchored in the world as it is, rather than the world as we might want it to be. Thus, we draw on this principle to name and deliberately work to disrupt the dominant assumptions and status quo-bound systems that reinforce intersectional racial injustices and relations as we seek to imagine and implement more just futures.

\section{Enacting Solidarities in Collective Change-Making}

Solidarity-driven forms of codesign orient and build from long histories of mobilizing inquiry in solidarity with the change-making of youth, families, and communities impacted by injustices (Bang \& Vossoughi, 2016). This principle orients us beyond "how do" descriptive questions that build knowledge about how we came to the current structures, systems, practices, and outcomes. Instead, we seek to open "how can" questions that co-construct knowledge and envision beyond our existing systems and structures, even amidst the profound challenges in education.

This principle also orients us to the "here and now" relationships that constitute both process and product in solidarity-driven codesign. Across the design conversations, we reached for what scholars have called a "proleptic politic" (Cole, 1998), or what CADRE organizer Maisie Chin refers to as "realizing the future in the present." That is, we aimed to prefigure solidarity relations through the process of designing and imagining justice and wellbeing. However carefully structured or facilitated, no design process will be free of the powered dynamics and normative assumptions that shape our daily lives; instead, the momentto-moment interactions in codesign work became opportunities to intervene in inequitable or problematic relations and systemic tensions. Building solidarities across and with difference constitutes a key aim of the work to enact transformative and consequential forms of learning and activity.

\section{Cultivating Ongoing Transformative Possibilities}

This principle attends to the process of educational change-making as an ongoing process that unfolds across contexts, communities, disciplines, institutions, and generations. Unlike the technical-rational and settler colonial logics of dominant white institutional systems and mainstream education reform, the work of codesign does not aspire to singular solutions or one-size-fits-all "silver bullets" that reinforce the current system logics. Instead, we posit that design with families and communities towards educational justice and communitydetermined wellbeing works to transform power and possible futures by drawing on heterogeneous disciplines, theories, and knowledge towards multiplicities. When taken up in ways that are consistent with this principle, solidarity-driven codesign cultivates relations and activity that ripple across space, time, and communities to engender ongoing possibilities and futurities for learning and living. This requires deliberate time and space for "social dreaming" (Espinoza, 2008) rooted in community knowledges and practices; lived through solidarities 
that reckon with our unique histories and interdependencies (Gaztambide-Fernández, 2012); and iteratively enacted as justice-making for collective continuance (Whyte, 2017).

\section{Grounding Principles in Local Contexts \& Communities}

Through the FLDC network, we subsequently catalyzed a series of design circles to "ground truth" the principles and open new imaginative spaces and futurities across ten distinct geographical, racial, and cultural communities. FLDC partners facilitated design circles with urban Indigenous communities and Persian school families in Chicago, Toisanese (Chinese) families in Southeast Seattle, Latinx families in suburban Salem, Oregon, Black and Brown parents in South Central Los Angeles, Latinx families and educators in West Salt Lake City, Black childcare and early education providers in rural Greenville, Mississippi, multiracial youth and community organizers in Detroit, immigrant mothers in suburban Rhode Island, and Black parents and principals in Southfield, Michigan. Although the design circles varied by context and how they took up solidarity-driven codesign (as a continuation of existing work or as new work), all the efforts worked to address these principles to different extents across 3 to 5 sessions. These initial design circles aimed to expand possibilities for change and catalyze transformative visions that might evolve into further implementation-focused codesign. We subsequently supported a second, more in-depth set of codesign efforts with a subset of 4 of these collaboratives to evolve our methodological and facilitative practices and engender new forms of family-community-educator activity and inquiry towards justice and wellbeing.

\section{About the JFDE Special Sections}

The two articles in this special section of JFDE constitute the first of two sections of the journal focused on the work of the FLDC. In designing with the solidarity-driven codesign principles, the first two papers illuminate distinct immigrant codesigns that opened new conceptual and relational possibilities for change as participants grappled with tensions of identity, relationality, and complex personhood amid profound historical and sociopolitical challenges to raising and educating their children. Kuttner, Yanagui, López, Barton, \& MayerGlenn (this issue) revisit a school-based budget decision-making body with Latinx families and educators. They examine how the group-centered contradictions of a policy intended to mandate parent voice in ways that fostered emergent solidarities across roles, race, culture, and experiences. The authors raise crucial questions about how to continuously cultivate opportunities for humanizing family-educator relations amidst school-centered engagement regimes and ongoing challenges, such as the covid pandemic and recently, state policymaking targeting "critical race theory" in schools.

Vossoughi takes up the thread of complex personhood, racial identity, and sociopolitical dynamics in her paper about intergenerational codesign with Iranian families in a Persian language school. Amid the 2016 election and Muslim ban, these design circles offered relational insights into the complex political tensions that emerged through the cultivation of a space of learning, as families grappled with sometimes contradictory narratives about race and identities. The author invites us to treat the stories and concerns in such dialogic social relations as "portals of meaning" that - over time -

might seed self-determining futurities and solidarities.

In the upcoming second section, we share papers that examine how sustained engagement shape our theories of change across contexts and time; how intergenerational 
learning enacted everyday resurgence and global Indigeneities; and how Black and brown parent leaders took up "rehearsals" as a practice for re-humanizing relations with educators to disrupt the school-to-prison pipeline. Finally, the commentary looks across the two sections to illuminate implications for teachers, leaders, and educational systems. The scholarship across these sections seeks to create spaces to develop knowledge, everyday practices, and relational leadership to envision transformative relations and change for families and education beyond a school-centered, ahistoric paradigm. Collectively, we hope they open the landscape of possibilities in the field to imagine anew what we need to cultivate just education.

\section{References}

Artiles, A. J. (2011). Toward an Interdisciplinary Understanding of Educational Equity and Difference: The Case of the Racialization of Ability. Educational Researcher, 40, 431445.

Anderson, J. D. (2004). Crosses to bear and promises to keep. Urban Education, 39(4), 359373.

Bang, M., Faber, L., Gurneau, J., Marin, A., \& Soto, C. (2016). Community-based design research: Learning across generations and strategic transformations of institutional relations toward axiological innovations. Mind, Culture, and Activity, 23, 28-41.

Bang, M., \& Vossoughi, S. (2016). Participatory design research and educational justice: Studying learning and relations within social change making. Cognition and Instruction, 34(3), 173-193.

Baquedano-López, P., Alexan der, R.A., Hernandez, S.J. (2013). Equity issues in parental and community involvement in schools: What teacher educators need to know. Review of Research in Education, 37(1), 149-182.

Bell, D. A., Jr. (1980). Brown v. Board of Education and the interest-convergence dilemma. Harvard Law Review, 93, 518-533.

Brayboy, B.M.J. (2005). Toward a tribal critical race theory in education. The Urban Review, $37(5), 425-446$.

Cajete, G. A. (2016). Indigenous education and the development of indigenous community leaders. Leadership, 12(3), 364-376. https:/ / doi.org/10.1177/1742715015610412

Cole, M. (1998). Cultural psychology: A once and future discipline. Harvard University Press.

Espinoza, M.L. (2008). Humanization and social dreaming: A case study of changing social relations in a summer migrant educational program. (Doctoral Dissertation). Retrieved from ProQuest: 3302577.

Engeström, Y. (2004). New forms of learning in co-configuration work. Journal of Workplace Learning, 16(1/2), 11-21

Fryberg, S.A., \& Bang, M. (2018, July 09). Blaming parents of color for their own oppression is an American pastime. Education Week. Retrieved January 23, 2019, from https:/ / www.edweek.org/ew/articles/2018/06/29/blaming-parents-of-color-fortheir-own.html

Gaztambide-Fernández, R.A. (2012). Decolonization and the pedagogy of solidarity. Decolonization: Indigeneity, Education \& Society, 1(1), 41-67.

Gutiérrez, K. D., \& Jurow, A. S. (2016). Social design experiments: Toward equity by design. Journal of the Learning Sciences, 25, 565-598.

Harris, C. I. (1993). Whiteness as property. Harvard Law Review, 1707-1791.

Hooks, B. (2003). Teaching community: A pedagogy of hope (Vol. 36). Psychology Press. 


\section{Journal of Family Diversity in Education}

Ishimaru, A. M., \& Bang, M. (2016). Toward a transformative research and practice agenda for racial equity in family engagement. Seattle, WA: Family Leadership Design Collaborative.

Ishimaru, A. M., \& Takahashi, S. (2017). Disrupting racialized institutional scripts: Toward parent-teacher transformative agency for educational justice. Peabody Journal of Education, 92(3), 343-362.

Ishimaru, A.M, Rajendran, A., Nolan, C.M, Bang, M. (2018). Journal of Family Diversity in Education, 3(2), 38-63.

Kaba, M. (2021). We do this til we free us: Abolitionist organizing and Transforming justice. Haymarket Books.

Kelley, R. D. (2002). Freedom dreams: The black radical imagination. Beacon Press.

Khalifa, M. (2018). Centering ancestral knowledges: Leadership in learning environments. The Family Leadership Design Collaborative.

Ladson-Billings, G. (2006). From the achievement gap to the education debt: Understanding achievement in US schools. Educational Researcher, 35, 3-12.

Love, B. L. (2019). We want to do more than survive: Abolitionist teaching and the pursuit of educational freedom. Beacon Press.

Meiners, E. R. (2011). Ending the School-to-Prison Pipeline/Building Abolition Futures. The Urban Review, 43(4), 547. https:/ / doi.org/10.1007/s11256-011-0187-9

Mignolo, W. D. (2007). Delinking: The rhetoric of modernity, the logic of coloniality and the grammar of de-coloniality. Cultural studies, 21(2-3), 449-514

Niemann, Y. F. (2012). Lessons from the experiences of women of color working in academia. Presumed incompetent: The intersections of race and class for women in academia, 446-499.

Orfield, G., \& Frankenberg, E. (2014). Increasingly Segregated and Unequal Schools as Courts Reverse Policy. Educational Administration Quarterly, 50(5), 718-734. https:/ / doi.org/10.1177/0013161X14548942

Smith, L.T. (1999). Decolonizing methodologies: Research and indigenous peoples. New York, NY: Zed Books Ltd.

Vizenor, G. R. (2008). Survivance: Narratives of native presence. University of Nebraska Press.

Walker, V. S. (1996). Their highest potential: An African American school community in the segregated South. Univ of North Carolina Press.

Whyte, K.P. (2017). Food Sovereignty, Justice and Indigenous Peoples: An Essay on Settler Colonialism and Collective Continuance. Oxford Handbook on Food Ethics. Edited by A. Barnhill, T. Doggett, and A. Egan. Oxford University Press.

Yosso, T. J. (2005). Whose culture has capital? A critical race theory discussion of community cultural wealth. Race ethnicity and education, 8(1), 69-91.

Yull, D., Wilson, M., Murray, C., \& Parham, L. (2018). Reversing the Dehumanization of Families of Color in Schools: Community-Based Research in a Race-Conscious Parent Engagement Program. School community journal, 28(1), 319-347. 
